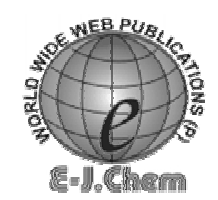

http://www.e-journals.net
ISSN: 0973-4945; CODEN ECJHAO

E-Journal of Chemistry

Vol. 5, No. 2, pp.331-341, April 2008

\title{
Mechanistic Investigation of Oxidation of Phenyl- propanolamine with $N$-Bromobenzenesulfonamide in Alkaline Medium: A Kinetic Approach
}

\author{
NINGEGOWDA PRASAD and KIKKERI N. MOHANA* \\ Department of Studies in Chemistry, University of Mysore, \\ Manasagangotri, Mysore-570 006, India \\ knmsvp@yahoo.com; Tel: 94496-27573
}

Received 12 June 2007; Accepted 10 August 2007

\begin{abstract}
The kinetics of oxidation of phenylpropanolamine (PPA) with sodium $N$-bromobenzenesulfonamide or bromamine-B (BAB) has been investigated in alkaline medium at $308 \mathrm{~K}$. The oxidation reaction obeys the rate law, $-\mathrm{d}[\mathrm{BAB}] / \mathrm{dt}=\mathrm{k}[\mathrm{BAB}][\mathrm{PPA}]^{\mathrm{x}}\left[\mathrm{OH}^{-}\right]$, where $\mathrm{x}$ is less than unity. The variation of ionic strength of the medium, addition of the reduction product, benzenesulfonamide, and chloride ion had no pronounced effect on the reaction rate. Decrease of dielectric permittivity of the medium by increasing the $\mathrm{CH}_{3} \mathrm{CN}$ content increased the rate. The reaction was studied at different temperatures and the activation parameters have been evaluated from the Arrhenius plot. The stiochiometry of the reaction was found to be $1: 1$, and the oxidation product of phenylpropanolamine was identified as benzaldehyde and ethylideneamine. The rate decreased in $\mathrm{D}_{2} \mathrm{O}$ medium and the normal isotope effect $\mathrm{k}^{\prime}\left(\mathrm{H}_{2} \mathrm{O}\right) / \mathrm{k}^{\prime}\left(\mathrm{D}_{2} \mathrm{O}\right)$ is 2.18. Proton inventory studies have been made in $\mathrm{H}_{2} \mathrm{O}-\mathrm{D}_{2} \mathrm{O}$ mixtures. Formation and decomposition constant of BAB-PPA complexes in the reaction scheme have been determined. The conjugate acid, $\mathrm{C}_{6} \mathrm{H}_{5} \mathrm{SO}_{2} \mathrm{NHBr}$ is assumed to be the reactive species. The proposed mechanism and the derived rate law are consistent with the observed experimental results.
\end{abstract}

Keywords: Phenylpropanolamine, Oxidation kinetics, Alkaline medium, Bromamine-B.

\section{Introduction}

The chemistry of $N$-metallo- $N$-aryl halosulfonamides, generally known as organic haloamines is of interest due to their diverse behavior. Their versatile nature is due to their ability to act as sources of halonium cations, hypohalite species and nitrogen anions, which act as both electrophiles and nucleophiles. The manohaloamines are two-electron oxidants while dihaloamines undergo four-electron change. As a result, these compounds react with a wide range of functional groups and affect a variety of molecular changes. The important member of this group is chloramine-T (CAT), which is a by-product of saccharin manufacture. Although mechanistic aspects of many reactions of chloramine- $T$ and 
chloramine-B $(\mathrm{CAB})$ have been well documented ${ }^{1-6}$, similar studies on bromine analogues are scanty. Bromamine- $\mathrm{B}\left(\mathrm{C}_{6} \mathrm{H}_{5} \mathrm{SO}_{2} \mathrm{NBr} \mathrm{Na}\right.$. $\left.1.5 \mathrm{H}_{2} \mathrm{O}\right)$, the bromine analogue of $\mathrm{CAB}$, is gaining importance as a mild oxidant and is found to be a better oxidizing agent than chlorocompounds. However, a little information exists in the literature on $\mathrm{BAB}$ reactions $^{7-10}$, particularly with respect to the oxidation kinetics of pharmaceuticals, which may throw some light on the mechanism ${ }^{11}$ of the metabolic conversion in biological systems. In view of this, there is a considerable scope for the study of BAB to get better insight of the speciation of $\mathrm{BAB}$ reaction models and understanding its redox chemistry in solution.

Phenylpropanolamine (PPA) is a drug of the phenylethylamine family used as a decongestant and also as an appetite suppressant. Although this drug does enhance weight $\operatorname{loss}^{12-14}$, the precise mechanism is unclear. PPA reduces food intake, body weight and carcass lipid in rats ${ }^{15}$. In veterinary medicine, it is used to control urinary incontinence in dogs.

In the light of the available information and of our continued interest on mechanistic studies of haloaminometric reactions in general, and medicinal compounds in particular the present investigation was under taken. The present paper reports for the first time the detailed kinetics of oxidation of phenylpropanolamine with $\mathrm{BAB}$ in presence of $\mathrm{NaOH}$ medium at $308 \mathrm{~K}$. The objectives of the present investigation are to (i) elucidate the reaction mechanism in alkaline solution, (ii) put forward appropriate rate law, (iii) ascertain the reactive species and (iv) identify the reaction products.

\section{Experimental}

Bromamine-B was prepared ${ }^{16}$ by partial debromination of dibromamine-B (DBB), which in turn was prepared by the bromination of chloramine-B (CAB). DBB (31.5g) was added in small quantities at a time and with constant stirring a $50 \mathrm{~mL}$ of $4 \mathrm{M}$ sodium hydroxide. The mass was cooled in ice, filtered under suction and the product was dried over anhydrous $\mathrm{CaCl}_{2}$. The available bromine was determine by iodometry (found: $27.9 \%$; requires: $28.04 \%$ ). It was further characterized by IR, ${ }^{1} \mathrm{H}$ and ${ }^{13} \mathrm{C}$ NMR spectroscopy. An aqueous solution of BAB was standardized iodometrically and was preserved in brown bottles to prevent photochemical deterioration. Pharmaceutical grade phenylpropanolamine hydrochloride (supplied by Cipla India Ltd., Mumbai, India) was used as received. All other chemicals used were of analytical grade. Ionic strength of the reaction mixture was kept constant $\left(\mu=0.2 \mathrm{~mol} \mathrm{dm}^{-3}\right)$ using a concentrated solution of $\mathrm{NaClO}_{4}$ in order to swamp the reaction. Solvent isotope studies was made with $\mathrm{D}_{2} \mathrm{O}(99.4 \%)$ supplied by the Bhabha Atomic Research Centre, Trambay, India. Doubly distilled water was used for preparing all aqueous solutions.

\section{Kinetic measurements}

The kinetic runs were carried out under pseudo-first-order conditions ( [substrate]>> [oxidant]) at constant temperature in glass stoppered Pyrex boiling tubes coated black on the outside to eliminate photochemical effects. Mixtures containing the requisite amounts of PPA, $\mathrm{NaOH}, \mathrm{NaClO}_{4}$ and water (to maintain a constant total volume for all runs) were placed in the tube and thermally equilibrated in a water bath set at a given temperature (308 $\pm 0.1 \mathrm{~K})$. To this was added a measured amount of a pre-equilibrated standard BAB solution to give a known concentration. The progress of the reaction was monitored iodometrically for two half-lives by withdrawing aliquots of the reaction mixture at regular time intervals. The pseudo-first-order rate constant, $\mathrm{k}^{\prime}$ calculated were reproducible within $\pm 4 \%$. Regression analysis of the experimental data to obtain regression coefficient, $r$, was calculated using a fx-570M statistical calculator. 


\section{Stoichiometry and product analysis}

Reaction mixtures containing varying compositions of BAB and PPA were kept at $308 \mathrm{~K}$ in presence of $0.013 \mathrm{~mol} \mathrm{dm}^{-3} \mathrm{NaOH}$ for $24 \mathrm{~h}$. The iodometric determination of unreacted $\mathrm{BAB}$ in the reaction mixture showed that one mole of $\mathrm{BAB}$ was consumed per mole of the PPA according to equation (1):

$$
\begin{aligned}
& \mathrm{C}_{9} \mathrm{H}_{13} \mathrm{NO}+\mathrm{RNClNa} \longrightarrow \mathrm{C}_{7} \mathrm{H}_{6} \mathrm{O}+\mathrm{C}_{2} \mathrm{H}_{5} \mathrm{~N}+\mathrm{RNH}_{2}+\mathrm{Na}+\mathrm{Cl}^{-} \\
& \text {where } \mathrm{R}=\mathrm{C}_{6} \mathrm{H}_{5} \mathrm{SO}_{2} .
\end{aligned}
$$

The products in the reaction mixture were extracted several times with diethyl ether. The combined ether extract was evaporated and subjected to column chromatography on silica gel $(60$ - $200 \mathrm{mesh})$ using gradient elusion (from dichloromethane to chloroform). The reduction product of $\mathrm{BAB}$, benzenesulfonamide was detected by paper chromatography ${ }^{17}$. Benzyl alcohol saturated with water was used as the solvent with $0.5 \%$ vanillin in $1 \% \mathrm{HCl}$ solution in ethanol as spray reagent $\left(\mathrm{R}_{\mathrm{f}}=0.88\right)$. It was further confirmed by its IR spectral data. The oxidation products of phenylpropanolamine were found to be benzaldehyde, and ethylidene amine and detected by spot test ${ }^{18}$. Benzaldehyde was identified by preparing 2, 4-DNP derivative. Further it was confirmed by IR spectrum, which showed a band at $1703 \mathrm{~cm}^{-1}$ for $>\mathrm{C}=0$ stretching and at $2846 \mathrm{~cm}^{-1}$ for aldehydic $\mathrm{C}-\mathrm{H}$ stretching mode. IR spectra were recorded using FT-IR (JASCO) spectrometer using $\mathrm{KBr}$ pellets.

\section{Results}

The oxidation of PPA with $\mathrm{BAB}$ has been kinetically investigated at different initial concentrations of the reactants in the presence of $\mathrm{NaOH}$ at $308 \mathrm{~K}$.

\section{Effect of varying reactant concentrations on the rate}

With the substrate in excess, at constant $[\mathrm{NaOH}]$, [PPA] ionic strength and temperature, the $[\mathrm{BAB}]_{0}$ was varied. Plots of $\log [\mathrm{BAB}]$ versus time were linear $(r>0.997)$ indicating a first-order dependence of the rate on $[\mathrm{BAB}]_{0}$. The pseudo-first-order rate constant, $\mathrm{k}^{\prime}$, calculated from the slopes are given in Table 1. Further, the values of $\mathrm{k}^{\prime}$ are unaltered with variation of $[\mathrm{BAB}]_{0}$ confirming the first-order dependence of the rate on $[\mathrm{BAB}]_{0}$.Under similar experimental conditions, the reaction rate increased with increase in $[\mathrm{PPA}]_{0}$ (Table 1). Plot of log k' versus $[\mathrm{PPA}]_{0}$ was linear (Fig.1, $\left.\mathrm{r}=0.996\right)$ with a slope less than unity (0.35) indicating a fractional-order dependence on [PPA $]_{0}$. Further, plot of $\mathrm{k}^{\prime}$ versus $[\mathrm{PPA}]_{0}$ was linear $(\mathrm{r}=0.997)$ having a $\mathrm{Y}$-intercept, confirming the fractionalorder dependence on $[\mathrm{PPA}]_{0}$.

\section{Effect of concentration of alkali on the rate}

When the $[\mathrm{NaOH}]_{0}$ was increased, keeping the other experimental conditions constant, the rate increased (Table 1). Plot of $\log \mathrm{k}^{\prime}$ versus $\log [\mathrm{NaOH}]$ was linear (Fig. 2; $\mathrm{r}=0.995$ ) with a slope of unity indicating first-order dependence of rate on $\left[\mathrm{OH}^{-}\right]$.

\section{Effect of benzenesulfonamide and chloride ion on the rate}

The reaction rate was unaffected by the addition of reduced product, benzenesulfonamide $\left(2 \times 10^{-4}\right.$ to $\left.8 \times 10^{-4} \mathrm{~mol} \mathrm{dm}^{-3}\right)$ indicating it was not involved in a pre-equilibrium with the oxidant. Also addition of $\mathrm{Cl}^{-}$in the form of $\mathrm{NaCl}\left(2.0 \times 10^{-2}\right.$ to $\left.8.0 \times 10^{-2} \mathrm{~mol} \mathrm{dm}^{-3}\right)$ had no significant effect on the reaction rate. 


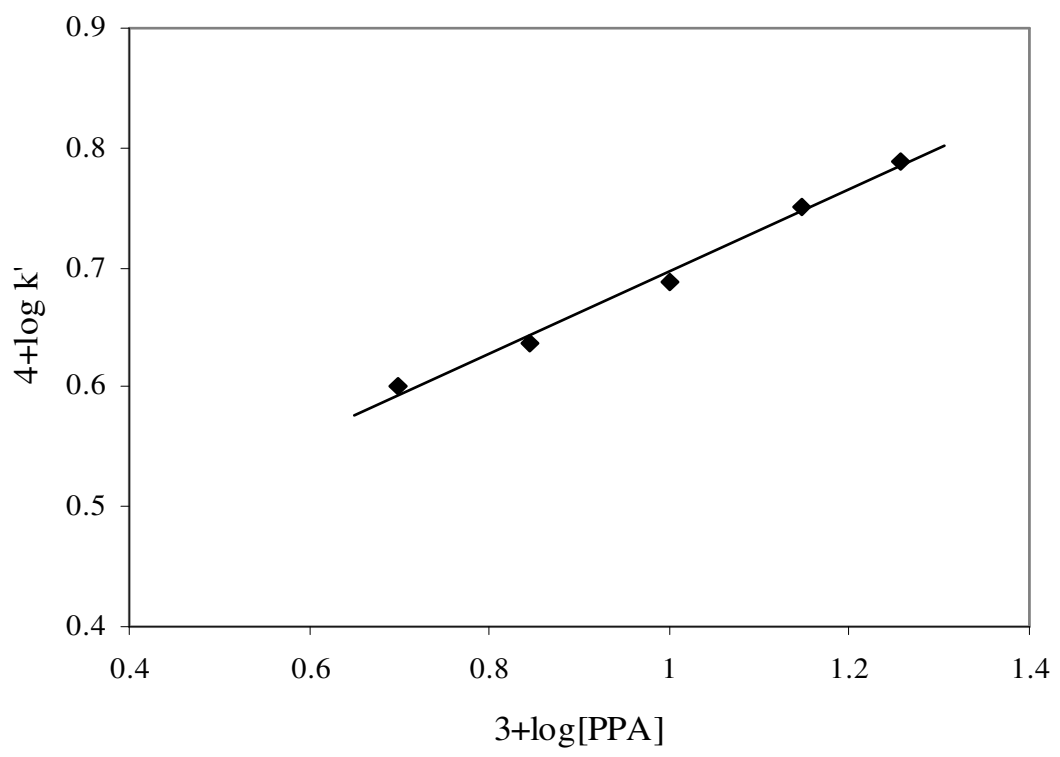

Figure 1. Plot of $4+\log \mathrm{k}^{\prime}$ versus $3+\log [\mathrm{PPA}]$

Table 1. Effect of varying concentrations of oxidant, substrate and alkali on the reaction rate at $308 \mathrm{~K}$.

\begin{tabular}{|c|c|c|c|}
\hline $\begin{array}{c}10^{4}[\mathrm{CAB}], \\
\mathrm{mol} \mathrm{dm}^{-3}\end{array}$ & $\begin{array}{c}10^{3}[\mathrm{PPA}], \\
\mathrm{mol} \mathrm{dm}^{-3}\end{array}$ & $\begin{array}{c}10^{3}[\mathrm{NaOH}] \\
\mathrm{mol} \mathrm{dm}^{-3}\end{array}$ & $\begin{array}{c}\mathrm{k}^{\prime} \times 10^{4}, \\
\mathrm{~s}^{-1}\end{array}$ \\
\hline 3.0 & 10.0 & 13.0 & 4.801 \\
\hline 5.0 & 10.0 & 13.0 & 4.885 \\
\hline 7.0 & 10.0 & 13.0 & 4.679 \\
\hline 9.0 & 10.0 & 13.0 & 4.898 \\
\hline 11.0 & 10.0 & 13.0 & 4.701 \\
\hline 5.0 & 5.0 & 13.0 & 3.991 \\
\hline 5.0 & 7.0 & 13.0 & 4.337 \\
\hline 5.0 & 10.0 & 13.0 & 4.885 \\
\hline 5.0 & 14.0 & 13.0 & 5.642 \\
\hline 5.0 & 18.0 & 13.0 & 6.141 \\
\hline 5.0 & 10.0 & 10.0 & 4.030 \\
\hline 5.0 & 10.0 & 13.0 & 4.885 \\
\hline 5.0 & 10.0 & 15.0 & 5.834 \\
\hline 5.0 & 10.0 & 17.0 & 6.602 \\
\hline 5.0 & 10.0 & 20.0 & 7.408 \\
\hline$* 5.0$ & 10.0 & 13.0 & 4.901 \\
\hline$* * 5.0$ & 10.0 & 13.0 & 4.782 \\
\hline${ }^{\mathrm{a}} 5.0$ & 10.0 & 13.0 & 4.802 \\
\hline $\mathrm{b}_{5} .0$ & 10.0 & 13.0 & 4.906 \\
\hline
\end{tabular}




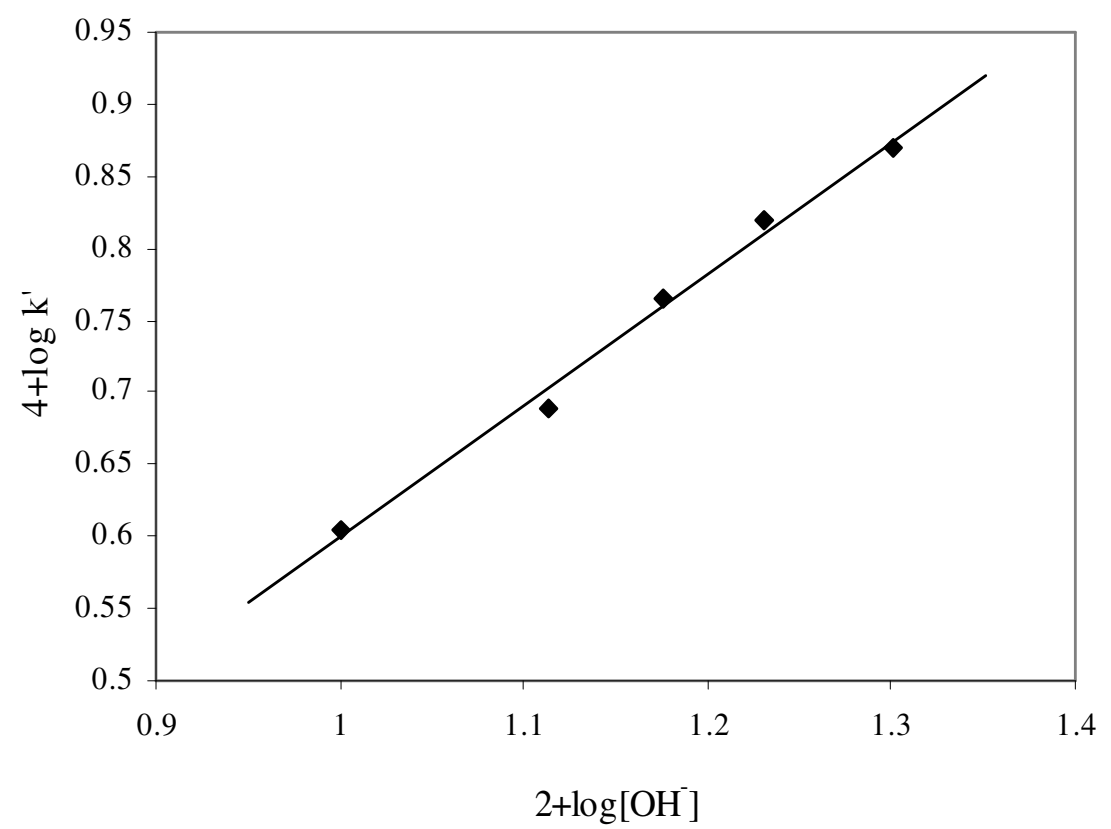

Figure 2. Plot of $4+\log \mathrm{k}^{\prime}$ versus $2+\log \left[\mathrm{OH}^{-}\right]$

\section{Effect of relative permittivity and ionic strength on the reaction rate}

The effect of relative permittivity (D) of the medium on the rate has been studied by varying the $\mathrm{CH}_{3} \mathrm{CN}-\mathrm{H}_{2} \mathrm{O}$ content in the reaction mixture with all other conditions kept constant. The values of relative permittivity were computed from the values of the pure liquids ${ }^{19}$. The rate constant, $\mathrm{k}^{\prime}$ increases with decreasing relative permittivity of the medium. The plot of $\log \mathrm{k}^{\prime}$ versus $1 / \mathrm{D}$ gave a straight line $(\mathrm{r}=0.998)$ with a positive slope. Blank experiments showed that, BAB did not oxidize PPA under the experimental conditions employed. The reaction rate remained unaffected by varying the ionic strength of the medium (by adding $\mathrm{NaClO}_{4}$ solution). Hence no attempt was made to keep the ionic strength constant for kinetic runs.

\section{Effect of solvent isotope on the rate}

As the rate is dependent as $\left[\mathrm{OH}^{-}\right]$, solvent isotope study in $\mathrm{D}_{2} \mathrm{O}$ medium was made. The value of $\mathrm{k}^{\prime}\left(\mathrm{H}_{2} \mathrm{O}\right)$ is $4.885 \times 10^{-4} \mathrm{~s}^{-1}$ and that of $\mathrm{k}^{\prime}\left(\mathrm{D}_{2} \mathrm{O}\right)=2.241 \times 10^{-4} \mathrm{~s}^{-1}$ leading to solvent isotope effect $\mathrm{k}^{\prime}\left(\mathrm{H}_{2} \mathrm{O}\right) / \mathrm{k}^{\prime}\left(\mathrm{D}_{2} \mathrm{O}\right)=2.18$. Proton inventory studies were made in $\mathrm{H}_{2} \mathrm{O}-\mathrm{D}_{2} \mathrm{O}$ mixtures and the results are shown in Table 3 . The corresponding proton inventory plot for the rate constant $\mathrm{k}^{\mathrm{n}}{ }_{\mathrm{obs}}$ in a solvent mixture containing deuterium atom fraction (n) is given in Fig.4.

\section{Effect of temperature on the rate}

The reaction was studied at different temperature $(303-321 \mathrm{~K})$ keeping other experimental conditions constant. The results are given in Table 2. From the linear Arrhenius plot of $\log \mathrm{k}^{\prime}$ versus $1 / \mathrm{T}$ (Fig. 3; $\mathrm{r}=0.997$ ), activation energy and other thermodynamic parameters were found to be $\mathrm{E}_{\mathrm{a}}=86.3 \mathrm{k} \mathrm{J} \mathrm{mol}^{-1} ; \Delta \mathrm{H}^{\ddagger}=83.7 \mathrm{~kJ} \mathrm{~mol}^{-1}$; $\Delta \mathrm{G}^{\neq}=78.0 \mathrm{~kJ} \mathrm{~mol}^{-1}$ and $\Delta \mathrm{S}^{\neq}=-37.5 \mathrm{JK}^{-1} \mathrm{~mol}^{-1}$. 
Table 2. Effect of varying temperature and dielectric permittivity on the rate

\begin{tabular}{ccc}
\hline Temperature, $\mathrm{K}$ & $\mathrm{CH}_{3} \mathrm{CN}, \%, \mathrm{v} / \mathrm{v}$ & $\mathrm{k}^{\prime} \times 10^{4}, \mathrm{~s}^{-1}$ \\
\hline 308 & 0 & 4.885 \\
308 & 10 & 5.527 \\
308 & 15 & 6.064 \\
308 & 20 & 6.871 \\
303 & - & 2.775 \\
308 & - & 4.885 \\
313 & - & 9.504 \\
318 & - & 15.353 \\
321 & - & 19.054 \\
\hline $\mathrm{CAB}]=5 \times 10^{-4} \mathrm{~mol} \mathrm{dm}^{-3} ;[\mathrm{PPA}]=10 \times 10^{-3} \mathrm{~mol} \mathrm{dm}^{-3} ;$ \\
{$[\mathrm{NaOH}]=13 \times 10^{-3} \mathrm{~mol} \mathrm{dm}^{-3} ; \mu=0.2 \mathrm{~mol} \mathrm{dm}^{-3}$}
\end{tabular}

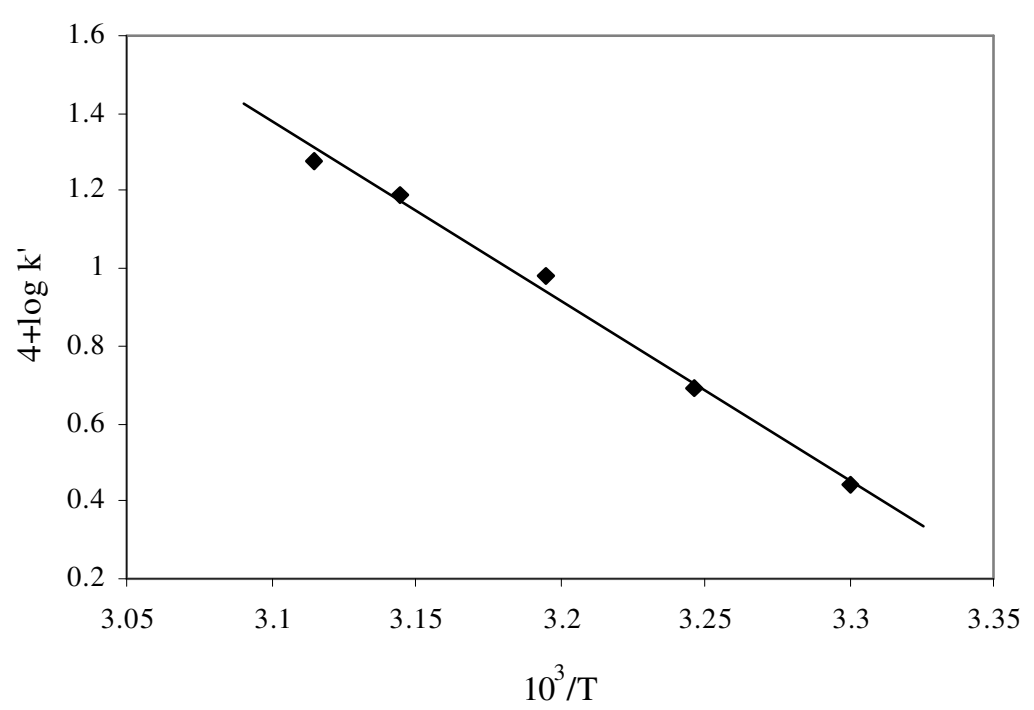

Figure 3. Plot of $4+\log \mathrm{k}^{\prime}$ versus $10^{3} / \mathrm{T}$

Table 3. Proton inventory studies for the oxidation of PPA in $\mathrm{H}_{2} \mathrm{O}-\mathrm{D}_{2} \mathrm{O}$ mixture at $308 \mathrm{~K}$

\begin{tabular}{cc}
\hline $\begin{array}{c}\text { Atom fraction of } \mathrm{D}_{2} \mathrm{O}, \\
(\mathrm{n})\end{array}$ & $\begin{array}{c}\mathrm{k}_{\mathrm{obs}} \times 10^{4} \\
\mathrm{~s}^{-1}\end{array}$ \\
\hline 0.00 & 4.855 \\
0.25 & 4.441 \\
0.50 & 3.688 \\
0.75 & 2.768 \\
0.85 & 2.341 \\
\hline $\mathrm{CAB}]=5 \times 10^{-4} \mathrm{~mol} \mathrm{dm}^{-3} ;[\mathrm{PPA}]=10 \times 10^{-3} \mathrm{~mol} \mathrm{dm}^{-3} ;$ \\
{$[\mathrm{NaOH}]=13 \times 10^{-3} \mathrm{~mol} \mathrm{dm}^{-3} ; \mu=0.2 \mathrm{~mol} \mathrm{dm}^{-3}$}
\end{tabular}




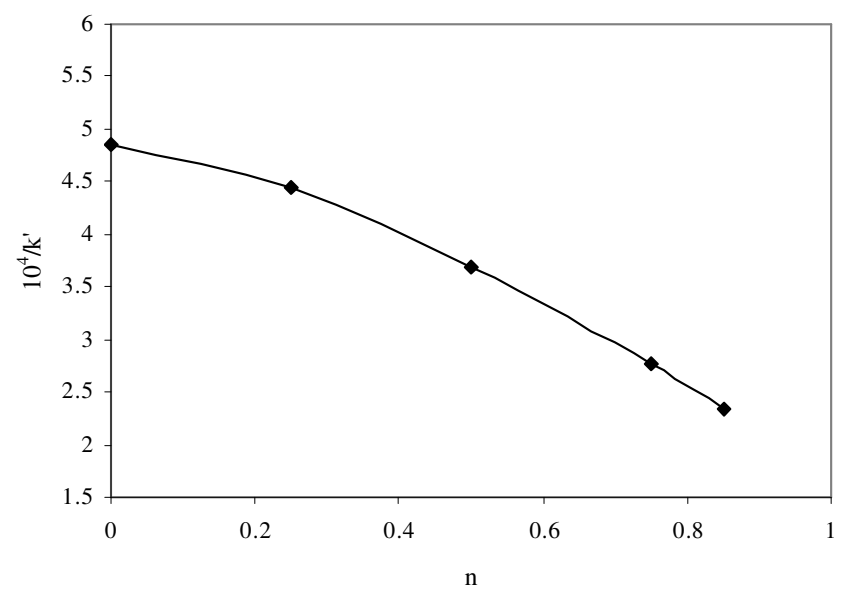

\section{Test for free radicals}

Figure 4. Plot of $10^{4} / \mathrm{k}^{\prime}$ versus $\mathrm{n}$.

The addition of aqueous acrylamide monomer solution to the reaction mixture in an inert atmosphere did not initiate polymerization indicating the absence of free radical species in the reaction sequence.

\section{Discussion}

The existence of similar equilibria in acid and alkaline solution of $N$-metallo- $N$-halo arylsulfonamide has been reported by Pryde and Soper ${ }^{20}$, Morris et.al. ${ }^{21}$, and Bishop and Jennings ${ }^{22}$. Bromamine-B like its chlorine analogues, chloramine-B and chloramine-T, behaves as a strong electrolyte in aqueous solution. The work of Hardy and Johnstan ${ }^{11}$ indicates the existence of following equilibria in acid and alkaline solution of $\mathrm{BAB}$,

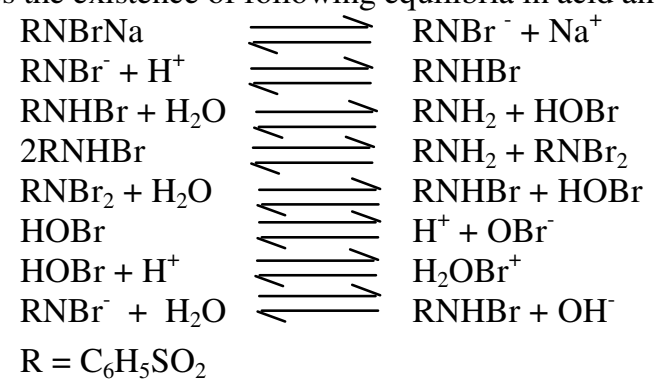

Thus the possible oxidizing species are $\mathrm{RNHBr}, \mathrm{RNBr}_{2}, \mathrm{HOBr}$ and probably $\mathrm{H}_{2} \mathrm{OBr}^{+}$in acid $\mathrm{BAB}$ solutions and $\mathrm{RNHBr}, \mathrm{HOBr}$ and $\mathrm{RNBr}^{-}$and $\mathrm{OBr}^{-}$in alkaline $\mathrm{BAB}$ solutions. The oxidation potential of $\mathrm{N}$-halosulfonamide system is $\mathrm{pH}$ dependent and decreases with increase in $\mathrm{pH}$ of the medium. In alkaline solutions of $\mathrm{BAB}, \mathrm{RNBr}_{2}$ does not exist at higher alkaline concentrations $^{22}$. In very dilute alkali concentrations $(\mathrm{pH}<11)$ the most likely species of BAB is RNHBr. Further, several workers ${ }^{23-25}$ have observed the increasing effect of $\left[\mathrm{OH}^{-}\right]$on the rate of reaction. This has been attributed to the formation of $\mathrm{RNBr}^{-}$from the conjugate acid. In the present investigations, the negligible influence of added benzenesulfonamide on the rate suggests that, $\mathrm{RNHBr}$ is the most likely oxidizing species in weak alkaline solution of $\mathrm{BAB}$. A fractionalorder dependence of rate as $[\mathrm{PPA}]_{0}$ indicates a pre-equilibrium before the rate determining step. Bearing these facts in mind, the following mechanism (Scheme 1) is proposed to account the observed kinetics: 


$$
\begin{gathered}
\mathrm{RNHBr}+\mathrm{OH}^{-} \frac{\mathrm{k}_{1}}{\mathrm{k}_{-1}} \mathrm{RNBr}^{-}+\mathrm{H}_{2} \mathrm{O} \text { fast } \\
\mathrm{RNBr}^{-}+\mathrm{PPA} \stackrel{\mathrm{k}_{2}}{\longrightarrow} \mathrm{X} \quad \text { slow and rds } \\
\mathrm{X} \quad \text { products fast }
\end{gathered}
$$

\section{Scheme 1}

In Scheme 1, X represents the complex intermediate species whose structure is shown in scheme 2, where a detailed mechanistic interpretation of PPA oxidation by BAB in alkaline medium is proposed.

From scheme 1 rate $=\mathrm{k}_{2}\left[\mathrm{RNCl}^{-}\right][\mathrm{PPA}]$

Applying steady state condition for $\mathrm{RNCl}^{-}$, it can be shown that,

$$
\left[\mathrm{RNBr}^{-}\right]=\frac{\mathrm{k}_{1}[\mathrm{RNHBr}]\left[\mathrm{OH}^{-}\right]}{\mathrm{k}_{-1}\left[\mathrm{H}_{2} \mathrm{O}\right]+\mathrm{k}_{2}[\mathrm{PPA}]}
$$

Substituting for [ $\left.\mathrm{RNBr}^{-}\right]$from equation (11) into equation (10), the following rate law (equation 12) is obtained:

$$
\text { rate }=\frac{\mathrm{k}_{1} \mathrm{k}_{2}[\mathrm{BAB}]\left[\mathrm{OH}^{-}\right][\mathrm{PPA}]}{\mathrm{k}_{-1}\left[\mathrm{H}_{2} \mathrm{O}\right]+\mathrm{k}_{2}[\mathrm{PPA}]}
$$

The rate law (12) is in agreement with the experimentally observed results.

Since rate $=k^{\prime}[B A B]$, equation (12) can be transformed into equations (13) and (14).

$$
\begin{aligned}
& \mathrm{k}^{\prime}=\frac{\mathrm{k}_{1} \mathrm{k}_{2}\left[\mathrm{OH}^{-}\right][\mathrm{PPA}]}{\mathrm{k}_{-1}\left[\mathrm{H}_{2} \mathrm{O}\right]+\mathrm{k}_{2}[\mathrm{PPA}]} \\
& \frac{1}{\mathrm{k}^{\prime}}=\frac{\text { or }}{\mathrm{k}_{1} \mathrm{k}_{2}\left[\mathrm{OH}^{-}\right][\mathrm{PPA}]}+\frac{1}{\mathrm{k}_{1}\left[\mathrm{OH}^{-}\right]}
\end{aligned}
$$

From the slopes and intercept of the linear double reciprocal plot of $1 / \mathrm{k}^{\prime}$ versus $1 /$ [PPA] (Fig. 5; $\mathrm{r}=0.988$ ) at fixed $\left[\mathrm{OH}^{-}\right]$, and $\left[\mathrm{H}_{2} \mathrm{O}\right]=55.5$, the values of $\mathrm{k}_{1}$ and $\mathrm{k}_{-1} / \mathrm{k}_{2}$ were found to be $6.056 \times 10^{-2} \mathrm{dm}^{-3} \mathrm{~mol}^{-1} \mathrm{~s}^{-1}$ and $1.036 \times 10^{-4}$ respectively.

A change in solvent composition by varying the $\mathrm{CH}_{3} \mathrm{CN}$ content in $\mathrm{CH}_{3} \mathrm{CN}-\mathrm{H}_{2} \mathrm{O}$ affects the reaction rate. The general equation relating to the effect of dielectric constant to the reaction rate in a bimolecular reaction has been derived by Landskroener and Laidler ${ }^{26}$. For the limiting case of zero angle of approach between two dipoles, Amis ${ }^{27}$ has shown that,

$$
\ln \mathrm{k}_{\mathrm{D}}^{\prime}=\ln \mathrm{k}_{\mathrm{D}=\infty}^{\prime}-\frac{2 \mu_{1} \mu_{2}}{\mathrm{DkTr}^{3}}
$$

Where $\mathrm{k}_{\mathrm{D}}^{\prime}$ is a function of dielectric constant $\mathrm{D}, \mu_{1}$ and $\mu_{2}$ are the dipole moments of reactions, $r$ is the distance of approach for two dipoles, $\mathrm{k}$ is the Boltzmann constant and $\mathrm{T}$ is the absolute temperature. Equation (15) predicts a linear relation between log k' versus 1/D. The slope of the line should be negative for a reaction between two dipole molecules and positive for ion-dipole reactions. In the present case, the plot of log $\mathrm{k}^{\prime}$ versus 1/D is linear with a positive slope, thus supporting the participation of ion-dipole species in the rate determining step. 


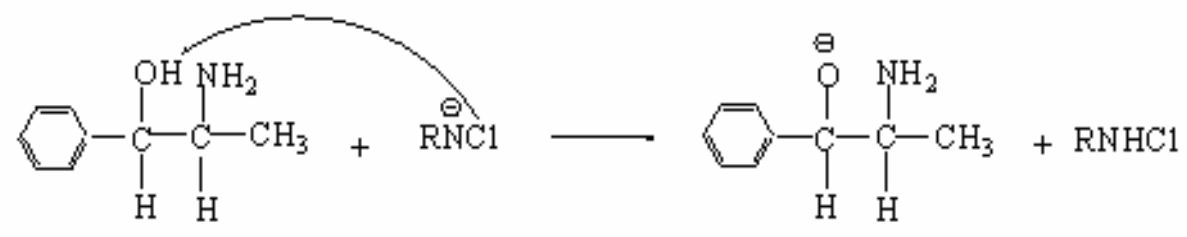<smiles>[GeH2]</smiles>

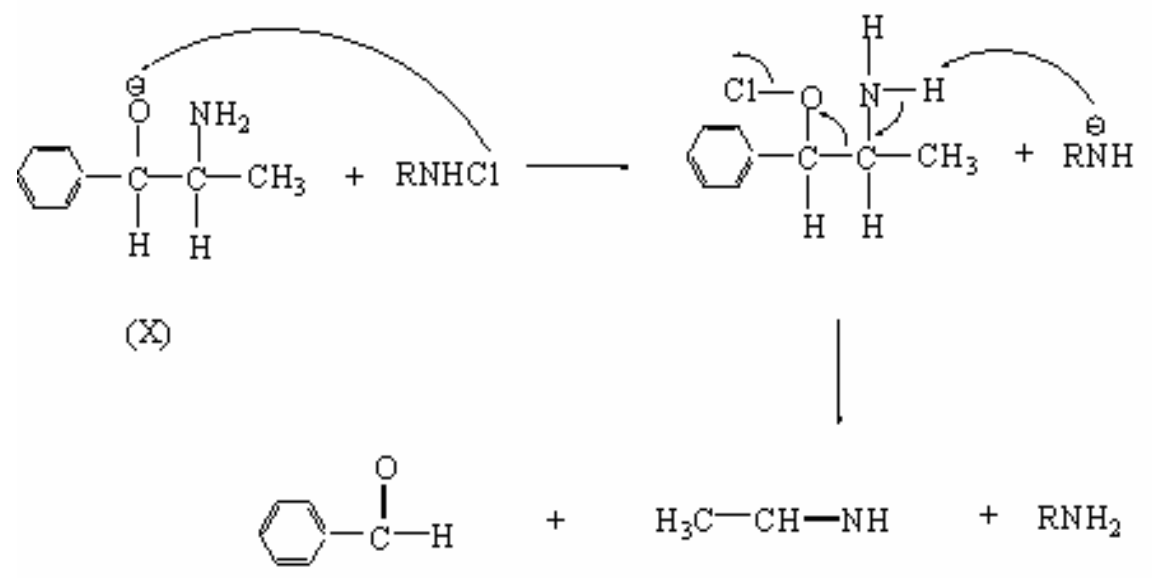

Scheme 2

The observed solvent isotope effect supports the proposed mechanism and the derived rate law. For a reaction involving a fast equilibrium $\mathrm{H}^{+}$or $\mathrm{OH}^{-}$ion transfer, the rate increases in $\mathrm{D}_{2} \mathrm{O}$ medium, since $\mathrm{D}_{3} \mathrm{O}^{+}$and $\mathrm{OD}^{-}$are stronger acid and stronger base respectively. In the present case, the observed solvent isotope effect of $k^{\prime}\left(\mathrm{H}_{2} \mathrm{O}\right) / \mathrm{k}^{\prime}\left(\mathrm{D}_{2} \mathrm{O}\right)>1$ is due to the greater basicity of $\mathrm{OD}^{-}$compared to $\mathrm{OH}^{-}$. However, the retardation of rate in $\mathrm{D}_{2} \mathrm{O}$ is due to the hydrolysis step which tends to make the normal kinetic isotope effect. The proton inventory studies made in $\mathrm{H}_{2} \mathrm{O}-\mathrm{D}_{2} \mathrm{O}$ mixture could throw light on the nature of the transition state. The dependence of the rate constant, $\mathrm{k}_{\mathrm{obs}}^{\mathrm{n}}$ on the deuterium atom fraction ' $\mathrm{n}$ ' in the solvent mixture is given by the following form of Gross-Butler equation ${ }^{28,29}$.

$$
\frac{\mathrm{k}_{\mathrm{obs}}^{0}}{\mathrm{k}_{\mathrm{obs}}^{\mathrm{n}}}=\frac{\pi \mathrm{TS}\left(1-\mathrm{n}+\mathrm{n} \phi_{\mathrm{i}}\right)}{\pi \mathrm{RS}\left(1-\mathrm{n}+\mathrm{n} \phi_{\mathrm{j}}\right)}
$$

Where $\phi_{\mathrm{i}}$ and $\phi_{\mathrm{j}}$ are isotope fractionation factor for isotopically exchangeable hydrogen sites in the transition state (TS) and in the ground/reactant state (RS), respectively. The Gross-Butler equation permits the evaluation of $\phi_{i}$ when the value of $\phi_{j}$ is known. However, the curvature of proton inventory plot could reflect the number of exchangeable proton in the reaction ${ }^{28}$. Plot of $\mathrm{k}_{\mathrm{obs}}^{\mathrm{n}}$ versus $\mathrm{n}$ (Fig.4) is a curve in the present case, and this in comparison with the standard curves, indicate the involvement of a single proton or H-D exchange in the reaction sequence ${ }^{30}$. This proton exchange is indicative of the participation of hydrogen ion in the formation of transition state. 


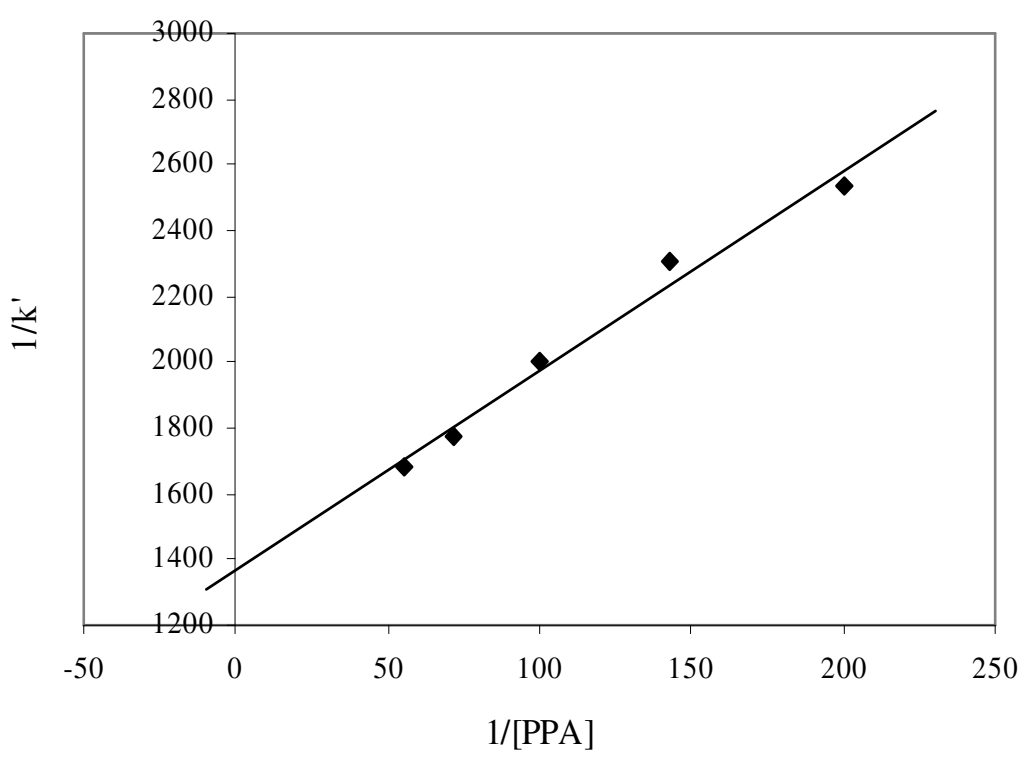

Figure 5. Plot of $1 / \mathrm{k}^{\prime}$ versus $1 /[\mathrm{PPA}]$

The mechanism is further supported by the value of energy of activation and other thermodynamic parameters. The fairly high positive values of free energy of activation and enthalpy of activation indicates that, the transition state is highly solvated, while the negative entropy of activation suggests the formation of the compact activated complex with fewer degrees of freedom. The reduction product $\left(\mathrm{RNH}_{2}\right)$ did not influence the rate, showing that it is not involved in pre-equilibrium. Addition of $\mathrm{Cl}^{-}$ion has no effect on the rate indicating that no free chlorine is formed in the reaction. All these observations also confirm the proposed mechanism and derived rate law.

\section{Acknowledgement}

The authors are thankful to University of Mysore, Mysore, for financial support.

\section{References}

1. Campbell M M and Johnson, G Chem. Rev. 1978, 78, 65.

2. Banerji K K, Jayaram B and Mahadevappa D S, J. Sci. Ind. Res.1987, 46, 65.

3. Bremner D H, Synthetic Reagents 1986, 6 ,9.

4. Mohana K N and Prasad N, J. Mol. Cat. A: Chemical, 2007,206 ,267.

5. Mohana K N, Rangaswamy and Lokanath Rai K M, Oxid. Communs. 2005, 28, 394.

6. Revathi S K, Ananda S, Mohana K N and Rangaswamy, Collect Czech. Chem. Commun. $2004,69,1577$.

7. Hardy F E and Johnston J P, J. Chem. Soc. Perkin Trans.2 1973, $2,742$.

8. Usha B N, Yathirajan H S and Rangaswamy, Indian J. Chem. 1984,23A, 685.

9. Kothari S and Banerji K K, Can. J. Chem. 1985,63, 2726.

10. Mallamma, Rangaswamy, Ananda S and Madegowda N M, Synth. React. Inorg. Met.Org.Chem. 2001, 31(8), 1479.

11. Isselbacher K J, Braunwald E, Wilson J D, Martin J B, Fauci A S and Kasper D L, Harrison's Principles of Internal Medicine, $13^{\text {th }}$ Ed., McGraw-Hill Inc, New York, 1994, pp 594-595, 597, $602 \& 881$. 
12. Weintraub M, Ginsberg G and Stein E C,. Clin. Pharmacol. Ther. 1986, 39, 501.

13. Weintraub M, J P.Kagen DV and Brody J S, Phenylpropanolamine: Risks, Benefits and Controversies, Philadelphia: Praeger Publishers, 1985, 53.

14. Schteingart DE, Int. J. Obes. 1992, 16, 487.

15. Wellman P J and Seller T L, Pharmacol. Biochem. Behav. 1986, 24, 605.

16. Ahmed M S and Mahadevappa D S, Talanta, 1980,27,669.

17. Raghavendra M P, Rangappa K S and Lokanatha Rai K M, J. Carbohydr. Chem. 1997,16, 343.

18. Feigl F, Spot Tests in Organic Analysis, Elsevier, Amsterdam, New York, 1966, 244-245.

19. Lide D R, CRC Hand Book of Chemistry and Physics, $73^{\text {rd }}$ Ed, London, CRC Press, 1992, 8-51.

20. Pryde D R and Soper F G, J. Chem. Soc. 1931, 1510.

21. Morris J C, Salazar J A and Wineman M A, J. Am. Chem. Soc. 1948,70, 2036.

22. Bishop E and Jennings V J, Talanta 1958, 1, 197.

23. Mohan K and Mahadevappa D S, Indian J. Chem. 1988, 27A , 702.

24. Thimmegowda B and Vijayalakshmi Rao R, J. Indian Chem. Soc. 1987, LXIV, 403.

25. Mahadevappa D S, Puttaswamy and Ananda S, Indian J. Chem. 1987, 26A, 33.

26. Landskroner D A and Laidler K J, Trans Faraday Soc. 1956, 52, 200.

27. Amis E S, Solvent Effects on Reaction Rates and Mechanisms, Academic Press, New York, 1966.

28. Albery W J and Davies M H, J. Chem .Soc. Faraday Trans. 1972, 68, 167.

29. Gopalakrishnan G and Hogg J L, J. Org. Chem.,1985, 50, 1206.

30. Isaacs N S, Physical Organic Chemistry, Wiley, New York, 1987, 275. 


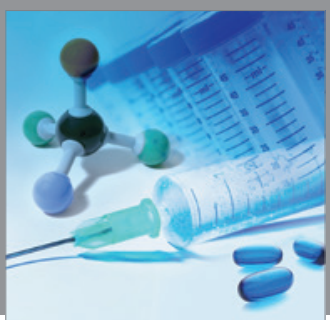

International Journal of

Medicinal Chemistry

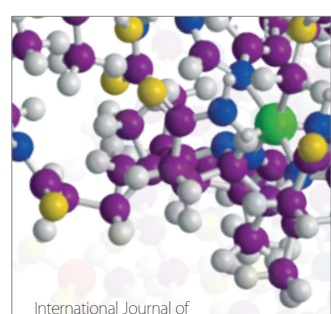

Carbohydrate Chemistry

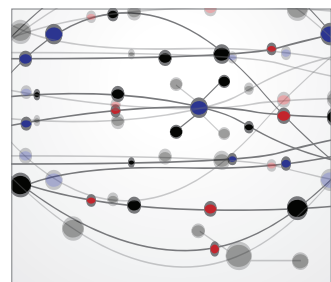

The Scientific World Journal
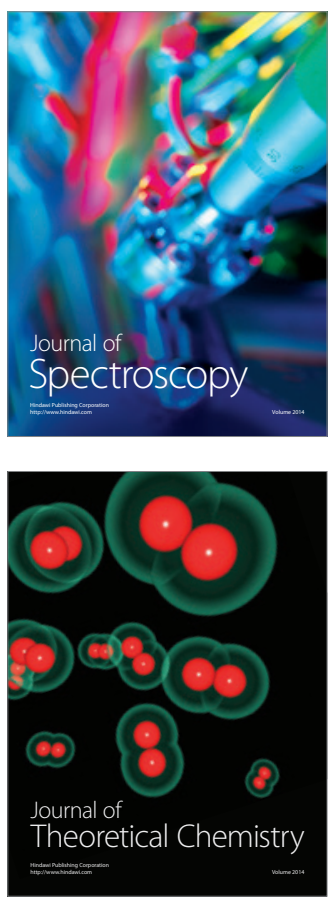
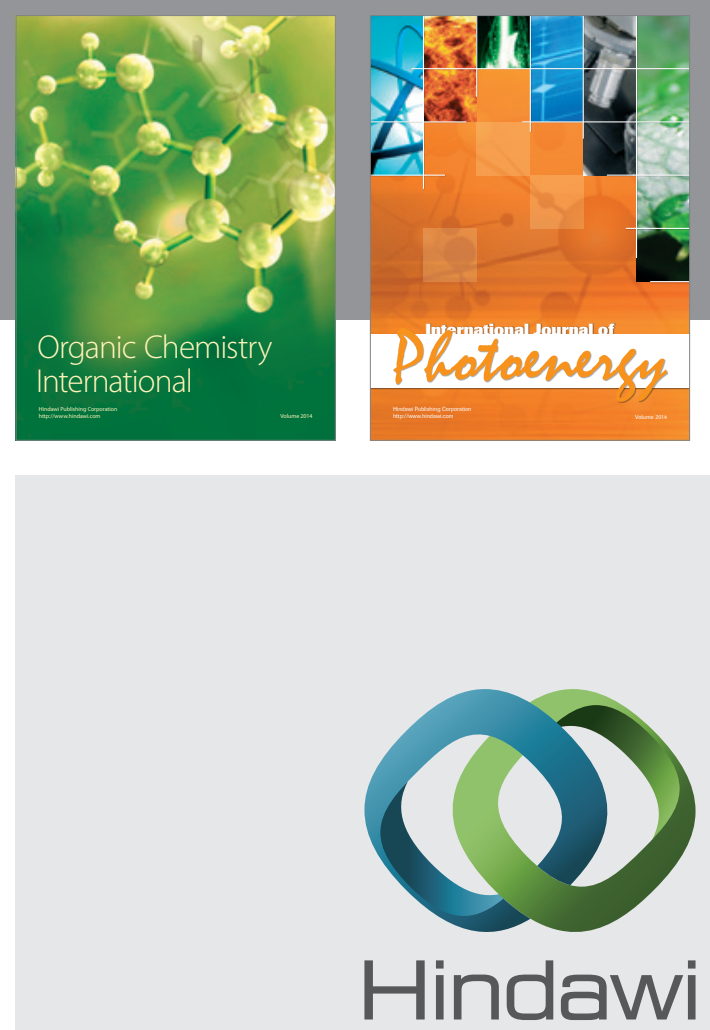

Submit your manuscripts at

http://www.hindawi.com
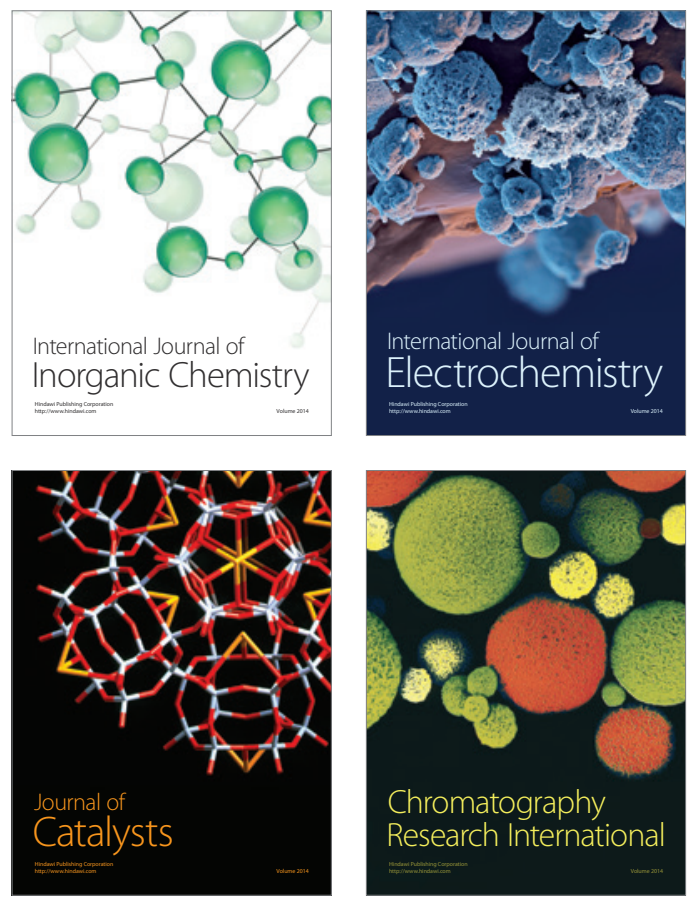
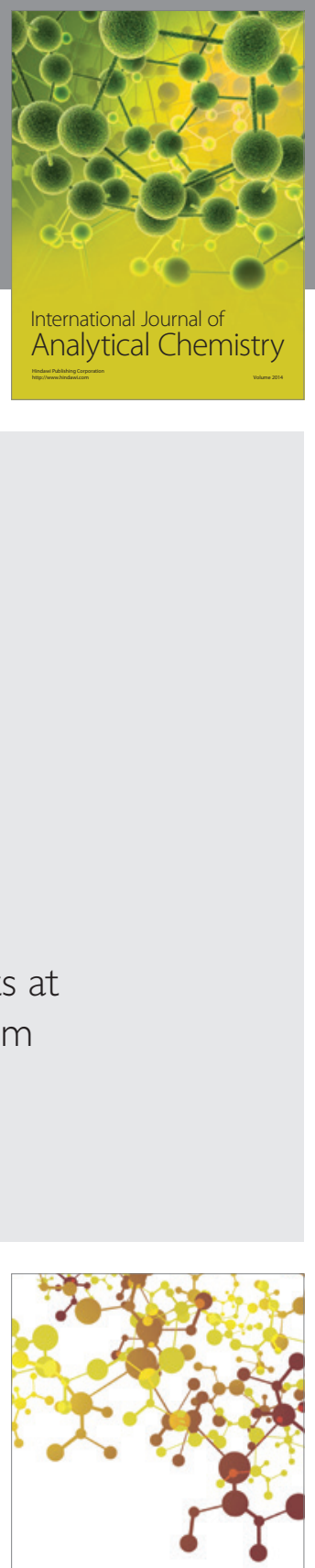

Journal of

Applied Chemistry
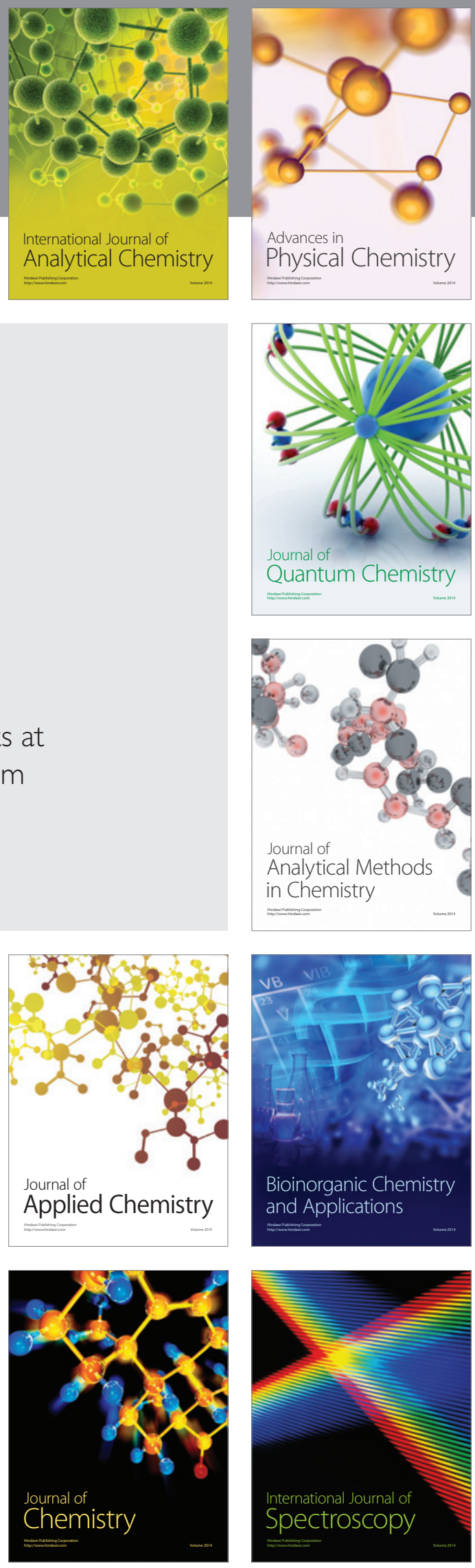